\title{
QUALIDADE BACTERIOLÓGICA DE OVOS CONTAMINADOS COM Pseudomonas aeruginosa E ARMAZENADOS EM TEMPERATURA AMBIENTE OU REFRIGERADOS
}

\author{
FERnanda Rodrigues MENDES ${ }^{1}$, NADJa Susana MogyCa LEANDRO ${ }^{2}$, Maria \\ AuXILIADORA ANDRADE ${ }^{2}$, MARCOS BARCELlOS CAFE ${ }^{2}$, ElIETE SOUZA SANTANA ${ }^{3}$, JosÉ \\ HENRIQUE STRINGHINI ${ }^{2}$
}

${ }^{1}$ Pós-graduanda da Escola de Veterinária e Zootecnia da universidade Federal de Goiás, Goiânia, GO, Brasil.

${ }^{2}$ Professores Doutores da Escola de Veterinária e Zootecnia da universidade Federal de Goiás, Goiânia, GO, Brasil mogyca@ufg.br

${ }^{3}$ Professora Doutora da Universidade Estadual de Goiás, Palmeiras de Goiás, GO, Brasil.

\begin{abstract}
Objetivou-se verificar o efeito da sanitização e da temperatura de armazenamento sobre a qualidade bacteriológica de ovos contaminados experimentalmente com Pseudomonas aeruginosa. Foram utilizados 240 ovos brancos em esquema fatorial $2 \times 2$ (lavados ou não e refrigerados ou não). Os ovos foram sanitizados com água quente contendo clorhexidina $20 \%$ e teor ativo $8 \%$ de cloro. Após a sanitização, foram contaminados com $1,5 \times 10^{5}$ unidades formadoras de colônia (UFCs) de Pseudomonas aeruginosa $/ \mathrm{mL}$ de solução e armazenados a $5{ }^{\circ} \mathrm{C}$ ou $25^{\circ} \mathrm{C}$ por 30 dias. A cada dez dias foram realizadas análises bacteriológicas e contagens de Pseudomonas aeruginosa na

casca e conteúdo. Foi realizada análise de variância e as médias comparadas pelo teste de Tukey. Pseudomonas aeruginosa foi isolada da casca e do conteúdo em todos os ovos, independentemente dos tratamentos. No entanto, quando os ovos foram sanitizados e armazenados a $5{ }^{\circ} \mathrm{C}$ apresentaram menor contagem bacteriana na casca e no conteúdo. Houve alta correlação entre Pseudomonas aeruginosa presente na casca com a presença no conteúdo do ovo quando os ovos não foram sanitizados e resfriados. Concluiu-se que para reduzir o crescimento bacteriano de Pseudomonas aeruginosa, os ovos devem ser sanitizados e mantidos a $5^{\circ} \mathrm{C}$ durante o armazenamento de 30 dias.
\end{abstract}

RESUMO

PALAVRAS-CHAVE: contaminação bacteriana; estocagem; ovos comerciais; temperatura.

\section{BACTERIOLOGICAL QUALITY OF WASHED AND UNWASHED EGGS STORED UNDER ROOM TEMPERATURE AND REFRIGERATION AND CONTAMINATED WITH Pseudomonas aeruginosa}

\section{ABSTRACT}

The aim of this study was to evaluate the effect of sanitization and storage temperature on the quality of commercial eggs inoculated with Pseudomonas aeruginosa. We used 240 large eggs, without cracks, from Dekalb White laying hens at 30 to 40 weeks of age. The experimental design used was two blocks in a 2 x 2 factorial arrange (washed/non-washed and refrigerated/non-refrigerated) with twelve replicates. The eggs were contaminated by handling, with $1.5 \times 10^{5}$ colony-forming units (CFU) of Pseudomonas aeruginosa and stored at $5{ }^{\circ} \mathrm{C}$ and $25^{\circ} \mathrm{C}$ for 30 days. Each ten days the eggshell and contents were submitted to bacteriological analyses. Variance analyses were performed and the data were compared by Tukey test. The results showed that Pseudomonas aeruginosa were isolated from the shells and contents of all eggs. Therefore, when the eggs were sanitized and stored at $5^{\circ} \mathrm{C}$ the contamination was less intense. The correlation between the presences of Pseudomonas aeruginosa in the shell and contents was high, when the eggs were not sanitized nor refrigerated. The conclusion of this study was that the egg must be sanitized and refrigerated when the stored for more than 30 days.

KEYWORDS: bacterial contamination; commercial eggs; storage; temperature. 


\section{INTRODUÇÃO}

O ovo é uma excelente fonte de proteínas e vitaminas e um alimento de baixo custo, disponível às populações de baixa renda. A produção de ovos com qualidade contribui para sua maior aceitação no mercado consumidor. Para isso, as características externas, como peso, cor, integridade da casca e uniformidade, assim como a manutenção da qualidade interna do ovo devem ser consideradas no processo de produção.

Além da preocupação com essas características, existe também uma preocupação referente à qualidade sanitária desse produto em toda a cadeia produtiva e da distribuição até o consumidor. A contaminação do ovo pode ocorrer em diferentes pontos na cadeia produtiva, no trato reprodutor da galinha, durante a formação do folículo da gema e/ou formação do albúmem no oviduto, antes da formação da casca ${ }^{3}$. Entretanto, alguns estudos microbiológicos revelam que a contaminação dos ovos ocorre, preferencialmente, após postura, para a maioria dos micro-organismos ${ }^{2}$. A disseminação horizontal é caracterizada pela contaminação bacteriana dos ovos na passagem pela cloaca ou no contato com o ambiente e na sua manipulação, sendo que existe uma correlação direta entre a contaminação do ambiente e a contaminação dos ovos ${ }^{3}$. Stringhini et al. ${ }^{4}$ isolaram Pseudomonas spp., Enterobacter spp. e Escherichia coli a partir das mãos, cavidade nasal e orofaringe de funcionários de uma granja de produção de ovos comerciais.

A casca constitui uma barreira física que protege o conteúdo do ovo; no entanto, ela é construída de grande número de poros, de diâmetros variáveis, os quais podem permitir a penetração de bactérias ${ }^{5}$. Além da casca, outros fatores, denominados intrínsecos, podem impedir a contaminação do ovo, tais como a cutícula, ou membranas da casca que também funcionam como barreiras mecânicas contra a invasão de microrganismos, atuando como filtros que retêm os microrganismos impedindo que eles atinjam o conteúdo dos ovos ${ }^{1}$.

Na tentativa de reduzir a contaminação por microrganismos patogênicos e deteriorantes, as cascas dos ovos podem ser lavadas e sanitizadas ${ }^{6}$. O processo de lavagem resulta em ovos de melhor aparência para comercialização e influencia na aceitação do produto pelo consumidor. No entanto, existe também a possibilidade da contaminação bacteriana via casca, no momento ou após a lavagem dos ovos. Mendes et al. ${ }^{7}$ demonstraram que ovos lavados apresentaram pior qualidade interna quando não foram refrigerados e concluíram que, se os ovos forem lavados, é necessário refrigerá-los. Stringhini et $\mathrm{al.}^{4}$, estudando a contaminação das cascas dos ovos por bactérias mesófilas após o procedimento de lavagem, em quatro granjas de ovos comerciais, verificaram que em duas granjas os procedimentos foram adequados, mas nas outras duas a contaminação dos ovos foi maior após a lavagem, mostrando, assim, que o procedimento pode apresentar falhas.

Dentre os microrganismos envolvidos na deterioração dos ovos e que possuem grande capacidade de atravessar a casca e suas membranas destaca-se o Pseudomonas aeruginosa. Trata-se de bastonete Gramnegativo aeróbio estrito, psicrotrófico, móvel com flagelação polar que está amplamente distribuído na natureza, sendo considerado um patógeno humano oportunista $^{8}$

Andrade et al. ${ }^{9}$ encontraram aproximadamente $16 \%$ dos ovos comercializados em diversos pontos varejistas de Goiânia contaminados com Pseudomonas spp.. Essas bactérias são proteolíticas e alteram as características sensoriais e físico-químicas do ovo pela produção de substâncias, como ácido e gás sulfídrico, amoníaco, aminas, indol e ureia, e pela oxidação de ácidos graxos. Do mesmo modo, Mendes et $\mathrm{al}^{7}$ observaram que a contaminação por Pseudomonas aeruginosa piorou a qualidade interna dos ovos, principalmente quando os ovos foram sanitizados (antes da contaminação) e não refrigerados.

Considerando que ovos podem ser contaminados após a sanitização, já que existe um risco de contaminação durante o período de manuseio pelos funcionários da sala de ovos, durante o armazenamento ou mesmo nos pontos de comercialização, este trabalho foi desenvolvido com o objetivo de verificar a qualidade bacteriológica de ovos sanitizados e depois contaminados experimentalmente, na casca, com Pseudomonas aeruginosa, e armazenados a $5{ }^{\circ} \mathrm{C}$ ou 25 ${ }^{\circ} \mathrm{C}$ durante 30 dias.

\section{MATERIAL E MÉTODOS}

Neste experimento foram utilizados 240 ovos, sem trincas, classificados como grandes e provenientes de poedeiras leves, com idade de 40 semanas de idade, da linhagem Dekalb White. Desses, 96 não foram contaminados, mas foram acompanhados sob condições semelhantes aos tratamentos, somente para controle de contaminação bacteriana.

O delineamento utilizado para as variáveis de qualidade dos ovos foi em blocos casualizados, sendo blocados os dois períodos de coletas (um em fevereiro e o outro em abril do mesmo ano). Estudou-se a combinação de dois fatores (sanitização x refrigeração), em esquema fatorial $2 \times 2$, com doze repetições cada, sendo o pool de três ovos a unidade experimental. Assim, foram estudados quatro tratamentos, sendo: ovos sanitizados e refrigerados; ovos sanitizados e não refrigerados; ovos nao sanitizados e refrigerados; ovos não sanitizados e não refrigerados.

Os ovos foram coletados no mesmo dia em uma granja comercial, sendo que ovos do grupo não sanitizados foram coletados diretamente no galpão de postura e os do grupo sanitizados passaram pela sala de ovos, onde foram submetidos à lavagem com sanitizante de acordo com a prática para a comercialização, ou seja, de forma mecanizada, com água a $10{ }^{\circ} \mathrm{C}$ acima da temperatura ambiente contendo clorhexidina a $20 \%$ e 
teor ativo de $8 \%$ e imediatamente encaminhados ao laboratório, onde foram submetidos à luz ultravioleta, em uma câmara asséptica por 24 horas, para reduzir a carga bacteriana normal da casca.

A solução para contaminação dos ovos foi preparada com Pseudomonas aeruginosa ATCC 9027 na concentração de $1,5 \times 10^{5} \mathrm{UFC} / \mathrm{mL}$ de solução salina esterilizada a $0,85 \%{ }^{4}$. Para obtenção do inóculo, a cepa foi repicada em ágar cetrimide e incubada a $37^{\circ} \mathrm{C}$, por 48 horas. Em seguida, as células foram suspensas em solução salina tamponada a $0,85 \%$ e mantidas a $4{ }^{\circ} \mathrm{C}$, já a concentração de $1,5 \times 10^{5} \mathrm{UFC} / \mathrm{mL}$ de solução salina esterilizada a $0,85 \%$ foi ajustada com auxílio da escala nefelométrica McFarland. As concentrações foram confirmadas pelo plaqueamento das diluições decimais seriadas em ágar cetrimide.

A contaminação dos ovos foi realizada em uma câmera asséptica grau II com auxílio de uma seringa tuberculina esterilizada. O inóculo de $0,1 \mathrm{~mL}$ de solução salina esterilizada tamponada a $0,85 \%$ contendo $1,5 \mathrm{x}$ $10^{5} \mathrm{UFC} / \mathrm{mL}$ de Pseudomonas aeruginosa foi depositado nas mãos revestidas com luvas, as quais foram descartadas após a inoculação de cada unidade. Cada ovo foi mantido por um período de, aproximadamente, 20 segundos nas mãos contaminadas, sendo sua superfície totalmente umedecida pela solução. Imediatamente após a inoculação, os ovos foram encaminhados para armazenamento, de acordo com o tratamento, em estufas BOD a $25^{\circ} \mathrm{C}$ ou para a geladeira a $5^{\circ} \mathrm{C}$, sendo as temperaturas controladas diariamente.

Para contagem bacteriana, a partir do primeiro dia, a cada dez dias, doze ovos de cada tratamento foram quebrados, sendo as cascas e conteúdos separados, formando-se pools de três cascas e de três conteúdos, separadamente. As cascas foram pesadas e acrescidas de solução salina peptonada $0,1 \%$ de acordo com o peso, constituindo a diluição $10^{\circ}$. O material foi homogeneizado manualmente por 25 vezes e diluições decimais sucessivas foram realizadas utilizando-se $9 \mathrm{~mL}$ de solução salina peptonada $0,1 \%$. Realizaram-se plaqueamentos por superfície com $0,1 \mathrm{~mL}$ de diferentes diluições em ágar cetrimide. Posteriormente, procedeuse à incubação a $37{ }^{\circ} \mathrm{C}$ por $48-72$ horas. A partir do décimo dia, seguiram-se os mesmos procedimentos, aumentando apenas os números das diluições para $10^{1}$, $10^{3}, 10^{5}$ e $10^{7}$. Após o período de incubação, UFCs de Pseudomonas aeruginosa foram contadas utilizando-se contador de colônias CP 600 plus Phoenix. Três UFCs por placa foram transferidas para tubos inclinados contendo ágar ferro-açúcar triplo (TSI) e incubadas a $37{ }^{\circ} \mathrm{C}$ por 24 horas. Após esse período, verificou-se a fermentação da glicose, da sacarose e da lactose em TSI e realizaram-se os seguintes testes bioquímicos: produção de urease, de indol e de $\mathrm{H}_{2} \mathrm{~S}$, citrato de Simmons, prova do vermelho de metila e prova de motilidade e malonato. O mesmo procedimento foi adotado com os conteúdos dos ovos, sendo o pool dos conteúdos de três ovos homogeneizados considerados como sendo a diluição $10^{\circ}$.

Os dados de contagens de Pseudomonas aeruginosa foram transformados em logaritmo decimal e expressos em log UFC/g e submetidos a análise de variância, sendo as médias, quando necessário, comparadas pelo Teste de Tukey a 5\% de probabilidade. Foi utilizado o programa Statistical Analysis System na versão $8, \mathrm{SAS}^{10}$. Foram realizadas as correlações estatísticas entre as variáveis: contagem de Pseudomonas aeruginosa na casca em relação à contagem dessa bacteria no conteúdo do ovo, para das datas de 10,20 ou 30 dias de armazenamento.

\section{RESULTADOS E DISCUSSÃO}

Os resultados da análise de variância para concentração bacteriana de Pseudomonas aeruginosa da casca dos ovos aos 10, 20 e 30 dias de armazenamento (Tabela 1) mostraram que houve interação significativa entre os grupos sanitizados e a temperatura de armazenamento para os períodos de 20 e 30 dias de armazenamento.

Com 10 dias de armazenamento, pôde-se observar que houve efeito somente da temperatura de armazenamento sobre a contagem bacteriana $(\mathrm{P}<0,05)$, sendo que ovos refrigerados durante o armazenamento apresentaram maior contagem de Pseudomonas aeruginosa, ou seja, a temperatura de $5^{\circ} \mathrm{C}$ não foi capaz de inibir o crescimento bacteriano no período de dez dias de armazenamento (Tabela 2).

Tabela 1- Valores de P da Análise de Variância dos resultados da contagem, em log, de Pseudomonas aeruginosa na casca de ovos sanitizados ou não, contaminados e armazenados a $5^{\circ} \mathrm{C}$ ou $25^{\circ} \mathrm{C}$ por 10,20 e 30 dias

\begin{tabular}{lccc}
\hline & \multicolumn{3}{c}{ PERÍODO DE ARMAZENAMENTO } \\
Grupos & 10 dias & 20 dias & 30 dias \\
\hline & & Valor de P & \\
Sanitização & 0,240 & 0,7321 & 0,130 \\
Temperatura & $0,005^{*}$ & 0,1174 & $0,0002^{*}$ \\
Sanitização *Temperatura & 0,408 & $0,0041^{*}$ & $0,0506^{*}$ \\
\hline Bloco & 0,260 & 0,0329 & 0,632 \\
\hline CV $(\%)$ & 24,35 & 28,161 & 46,59 \\
\hline
\end{tabular}


Esses resultados assemelham-se aos dados de Pinto e Silva ${ }^{11}$, que estudaram o comportamento da Salmonella Enteritidis na casca de ovos de consumo (lavados ou não), e observaram que, na temperatura de armazenamento de $8{ }^{\circ} \mathrm{C}$, o microrganismo permaneceu viável na superfície dos ovos até o final do período das análises de 336 horas, enquanto que na temperatura de $30{ }^{\circ} \mathrm{C}$ houve inibição e até eliminação do microorganismo da superfície da casca, após 72 horas. Os resultados sugerem que o comportamento, nesse período, do Pseudomonas aeruginosa, deste experimento foi semelhante ao comportamento da Salmonella Enteritidis. Não houve efeito da sanitização, ou seja, independentemente de os ovos terem sido ou não sanitizados, houve crescimento bacteriano na casca nesse período, mostrando, assim, que o sanitizante não apresentou um efeito residual na casca do ovo capaz de evitar o crescimento bacteriano, no início do armazenamento.

Tabela 2- Valores médios da contagem, em log, de Pseudomonas aeruginosa na casca de ovos sanitizados e armazenados a $5^{\circ} \mathrm{C}$ ou $25^{\circ} \mathrm{C}$ por 10 dias

\begin{tabular}{lcl}
\hline & Pseudomonas aeruginosa $(\log \mathrm{UFC} / \mathrm{g})$ & \\
\hline Sanitizados & 10 dias de armazenamento & Não \\
& Sim & 6,35 \\
\hline Temperatura de armazenamento & 5,69 & $5{ }^{\circ} \mathrm{C}$ \\
& $25^{\circ} \mathrm{C}$ & $6,89 \mathrm{~b}$ \\
\hline
\end{tabular}

Valores seguidos por letras diferentes na linha diferem entre si pelo teste de $\mathrm{F}(5 \%)$.

No período de 20 dias de armazenamento (Tabela 3), pôde-se observar que ovos sanitizados e resfriados apresentaram menor contagem da bactéria na casca $(\mathrm{P}<0,05)$ em relação aos grupos sanitizados e não resfriados. Esses resultados se repetiram aos 30 dias de armazenamento, mostrando, assim, que a melhor maneira de se armazenar ovos quando sanitizados é sob refrigeração. Dados semelhantes foram observados por Stringhini et al. ${ }^{4}$, que concluíram que ovos sanitizados devem ser armazenados sob refrigeração.

Tabela 3- Valores médios da contagem, em log, de Pseudomonas aeruginosa na casca de ovos sanitizados e armazenados a $5^{\circ} \mathrm{C}$ ou $25^{\circ} \mathrm{C}$ por 20 e 30 dias

\begin{tabular}{lcc}
\hline \multicolumn{3}{c}{ Pseudomonas aeruginosa $(\log \mathrm{UFC} / \mathrm{g})$} \\
\hline & 20 dias \\
\hline Temp. de armazenamento & Nanitizados \\
$25^{\circ} \mathrm{C}$ & & \\
$5{ }^{\circ} \mathrm{C}$ & $8,72 \mathrm{Ba}$ & $7,26 \mathrm{Aa}$ \\
\hline & $6,22 \mathrm{Aa}$ & $8,053 \mathrm{Aa}$ \\
\hline & 30 dias & \\
\hline Temp. de armazenamento & Sanitizados & Não sanitizados \\
$25^{\circ} \mathrm{C}$ & & \\
$5^{\circ} \mathrm{C}$ & $6,899 \mathrm{Ba}$ & $6,514 \mathrm{Aa}$ \\
\hline
\end{tabular}

Médias seguidas de letras iguais, minúscula (na linha) e maiúscula (na coluna), não diferem entre si pelo teste de Tukey(5\%).

Com relação à contagem do Pseudomonas aeruginosa no conteúdo dos ovos (Tabela 4), pôde-se observar que houve efeito da sanitização somente no período de 10 dias de armazenamento. Houve interação entre a sanitização e a temperatura de armazenamento quando os ovos foram armazenados por 20 dias. Não houve efeito dos tratamentos quando os ovos foram armazenados por 30 dias $(\mathrm{P}>0,05)$.

Aos 10 dias de armazenamento, ovos sanitizados apresentaram maior quantidade de Pseudomonas aeruginosa no conteúdo, independentemente da temperatura de armazenamento (Tabela 5). Portanto, o sanitizante não inibiu a migração da Pseudomonas da casca para o conteúdo do ovo. As barreiras mecânicas presentes na casca podem ter sido danificadas ou a bactéria se instalou desde o inicio nas membranas da casca, as quais atuam como filtros e retêm os microrganismos impedindo que eles atinjam o conteúdo dos ovos. E provavelmente no momento da preparação das amostras, antes de serem processadas, a bactéria se incorporou ao conteúdo do ovo. 
Tabela 4- Valores de P da Análise de Variância dos resultados da contagem, em log, de Pseudomonas aeruginosa no conteúdo de ovos sanitizados e armazenados a $5^{\circ} \mathrm{C}$ ou $25^{\circ} \mathrm{C}$ por 10,20 e 30 dias

\begin{tabular}{lccc}
\hline & \multicolumn{3}{c}{ Período de Armazenamento } \\
Tratamentos & 10dias & 20 dias & 30 dias \\
\hline Valor de P & & & \\
Sanitização & $0,0354^{*}$ & 0,964 & 0,219 \\
Temperatura & 0,7862 & 0,278 & 0,907 \\
Sanitização *Temperatura & 0,6430 & $0,002^{*}$ & 0,303 \\
\hline Bloco & 0,326 & 0,016 & 0,267 \\
\hline CV $(\%)$ & 28,74 & 28,73 & 29,74 \\
\hline
\end{tabular}

Por outro lado, Jones et al. ${ }^{12}$ observaram que ovos lavados apresentavam melhor qualidade microbiológica de conteúdo do que os não lavados para as análises de mesófilos, bolores e leveduras, Enterobacteriaceae e Pseudomonas spp. quando armazenados por dez semanas a $4^{\circ} \mathrm{C}$.

Com relação ao efeito da refrigeração durante o armazenamento (10 dias), pôde-se observar que foram encontradas bactérias no conteúdo dos ovos em todos os grupos estudados, mostrando, assim, que a refrigeração dos ovos não foi capaz de evitar a contaminação do conteúdo do ovo. Esses resultados podem ser respaldados por pesquisa realizada por De Reu et al. ${ }^{8}$, que constataram que bactérias Gram-negativas, como Pseudomonas spp., penetraram facilmente pelos poros das cascas dos ovos e que a contaminação interna ocorreu, frequentemente, após quatro a cinco dias de armazenamento.

Outro elemento que provavelmente facilitou a penetração da Pseudomonas aeruginosa foi a qualidade da casca, pois o teste de gravidade específica da casca revelou valores baixos em todos os grupos estudados e, de acordo com Carvalho et al. ${ }^{13}$, valores da gravidade específica abaixo de $1,080 \mathrm{~g} / \mathrm{cm}^{3}$ são considerados ruins para qualidade de casca. Stringhini et $\mathrm{al}^{4}{ }^{4}$ também verificaram que a espessura da casca influenciou na penetração da bactéria Pseudomonas aeroginosa para o conteúdo.

Tabela 5- Valores da gravidade específica (GE) da casca dos ovos e da contagem, em log, de Pseudomonas aeruginosa no conteúdo de ovos sanitizados e armazenados a $5{ }^{\circ} \mathrm{C}$ ou $25^{\circ} \mathrm{C}$ por 10 e 30 dias

\begin{tabular}{|c|c|c|c|}
\hline & $\begin{array}{c}\mathrm{GE} \\
(\mathrm{g} / \mathrm{cm} 3)\end{array}$ & $\begin{array}{r}\text { Pseudom } \\
\text { Perî }\end{array}$ & \\
\hline Tratamentos & & 10dias & 30 dias \\
\hline \multicolumn{4}{|l|}{ Sanitização } \\
\hline Sim & 1,066 & $6,842 b$ & 7,169 \\
\hline Não & 1,064 & $5,561 \mathrm{a}$ & 6,366 \\
\hline \multicolumn{4}{|c|}{ Temp. de armazenamento } \\
\hline $25^{\circ} \mathrm{C}$ & 1,062 & 6,190 & 6,805 \\
\hline $5^{\circ} \mathrm{C}$ & 1,068 & 6,212 & 6,730 \\
\hline
\end{tabular}

Valores seguidos por letras iguais diferentes na coluna, por grupo, não diferem entre si pelo teste de $\mathrm{F}(5 \%)$.

Houve interação significativa entre sanitização e temperatura de armazenamento para a contagem de Pseudomonas aeruginosa no conteúdo do ovo (Tabela 4) aos 20 dias de armazenamento e o desdobramento da interação está apresentado na Tabela 6. Os resultados estão em concordância aos observados com a contagem na casca do ovo, sendo que ovos sanitizados apresentaram menor $(\mathrm{P}<0,05)$ quantidade de Pseudomonas aeruginosa somente quando armazenados a temperatura de $5{ }^{\circ} \mathrm{C}$, mostrando a importância da refrigeração. Infelizmente, no Brasil, a refrigeração dos ovos durante o período de armazenamento ou de exposição em supermercados para a sua comercialização não é obrigatório. Neste experimento, os resultados indicam que, para manter a qualidade bacteriológica de ovos, o correto é a sanitização e a refrigeração durante a comercialização, já que o período de validade para o produto é de 30 dias. Pode-se observar que as contagens de UFCs nos conteúdos dos ovos contaminados, nos períodos de 10, 20 ou 30 dias de armazenamento, apresentaram valores médios em log, acima ou bem próximos de $6 \log \mathrm{UFC} / \mathrm{mL}$. Para Franco e Landgraf ${ }^{14}$, a contagem superior a $6 \log \mathrm{UFC} / \mathrm{g}$ de um alimento é sinal de deterioração e de alterações organolépticas, mesmo considerando variações nos 
padrões de interpretação com o tipo de alimento e do microrganismo. Portanto, desde a primeira avaliação (10 dias), de acordo com Franco e Landgraf ${ }^{14}$, os ovos encontravam-se fora dos padrões para consumo humano; entretanto, as alterações organolépticas só foram observadas aos 30 dias de armazenamento, quando constatou-se que muitos ovos se encontravam em processo de deterioração, apresentando albúmen verde e gema totalmente enegrecida. Esses resultados podem estar relacionados com a alta concentração do inóculo utilizado neste experimento.

Tabela 6 - Valores médios da contagem, em log, de Pseudomonas aeruginosa no conteúdo de ovos sanitizados e armazenados a $5{ }^{\circ} \mathrm{C}$ ou $25^{\circ} \mathrm{C}$ por 20 dias

\begin{tabular}{lcc}
\hline \multicolumn{3}{c}{ Pseudomonas aeruginosa $(\log \mathrm{UFC} / \mathrm{g})$} \\
\hline & Sanitizados & \\
\hline Temp. de armazenamento & & Não sanitizados \\
$25^{\circ} \mathrm{C}$ & $8,83 \mathrm{Ba}$ & $6,362 \mathrm{Aa}$ \\
$5{ }^{\circ} \mathrm{C}$ & $5,50 \mathrm{Aa}$ & $8,053 \mathrm{Aa}$ \\
\hline
\end{tabular}

Médias seguidas de letras iguais, maiúscula (na coluna) e minúscula(na linha), não diferem entre si pelo teste de Tukey(5\%).

As modificações nas estruturas dos ovos (odores, cores) demoraram semanas para ocorrer ${ }^{12}$. Barancelli ${ }^{15}$ relataram que a capacidade de sobrevivência ou de multiplicação dos microrganismos em um alimento depende de uma série de fatores. O resultado de interação neste experimento, no qual o melhor resultado foi a sanitização com a refrigeração do ovo, está de acordo com conceito dos obstáculos de Leistner, de que a ação conjunta de dois ou mais fatores podem potencializar ou limitar o desenvolvimento bacteriano, assim como permitir aumentar a vida de prateleira de um alimento e sua estabilidade microbiológica

De acordo com Franco e Landgraf ${ }^{14}$, inóculos acima de $1,5 \times 10^{4} /$ Pseudomonas aeruginosa é considerado elevado. No entanto, ocorrem situações, durante a produção dos ovos e/ou a manipulação e armazenamento, que possibilitam essa contaminação, sendo que a manipulação pode ocorrer por portadores inaparentes, o que pode resultar em contaminação cruzada no armazenamento. A presença de portadores inaparentes de Pseudomonas spp. que manipulam ovos foram reportadas por Stringhini et al. ${ }^{4}$, durante avaliação do perfíl microbiológico de mãos, da cavidade nasal e da orofaringe de funcionários de granjas de produção de ovos comerciais.

Resultados obtidos por Figueiredo et al. ${ }^{16}$ mostraram que o período de armazenamento de 28 dias sem refrigeração provocou uma perda de qualidade progressiva nos ovos de consumo e encontraram Pseudomonas spp. em 1,7\% dos ovos analisados, com um dia de armazenamento em temperatura ambiente. Esses autores consideraram que, embora a bactéria do gênero Pseudomonas não seja patogênica, ela pode provocar toxinfecções quando presente em alta concentração, além de provocar a deterioração dos ovos, com alterações de cor da gema e do albúmem, a desintegração do ovo e odor desagradável.

As correlações realizadas entre a contagem de Pseudomonas aeruginosa na casca em relação à contagem dessa bactéria no conteúdo do ovo, durante os períodos de armazenamento de 10,20 ou 30 dias, de acordo com os tratamentos (Tabela 7), mostraram que a não sanitização e não refrigeração dos ovos durante o armazenamento proporcionou maior probabilidade de penetração e desenvolvimento da bactéria Pseudomonas aeruginosa no conteúdo do ovo.

Tabela 7. Correlações entre a contagem de Pseudomonas aeruginosa na casca em relação a contagem no conteúdo do ovo durante os períodos de armazenamento de 10, 20 ou 30 dias de acordo com os tratamentos

\begin{tabular}{lccc}
\hline & \multicolumn{2}{c}{ Período de Armazenamento } \\
& 10 dias & 20 dias & 30 dias \\
\hline Tratamentos & & & \\
Sanitizado e não refrigerado & 0,06 & 0,47 & 0,61 \\
Sanitizado e refrigerado & 0,08 & 0,97 & 0,41 \\
Não sanitizados e não refrigerado & 0,96 & 0,63 & 0,98 \\
Não sanitizado e refrigerado & 0,30 & 0,73 & 0,05 \\
\hline
\end{tabular}




\section{CONCLUSÃO}

Para reduzir o crescimento bacteriano de ovos contaminados na casca por Pseudomonas aeruginosa e evitar a deteriorização interna, os ovos, quando sanitizados, devem ser armazenados a $5{ }^{\circ} \mathrm{C}$, durante todo o período de validade nos estabelecimentos comerciais (30 dias de armazenamento),

\section{REFERÊNCIAS}

1.Messens W, Grijspeerdt K, Herman L. Eggshell penetration by Salmonella: a review. World Poultry Sci J. 2005 jan; 61(1): 71-85.

2.Manual de Segurança e Qualidade para Avilcultura de Postura, Brasilia: EMBRAPA/SEDE, 2004. 97 p. (Qualidade e Segurança dos Alimentos). http://ainfo.cnptia.embrapa.br/digital/bitstream/item/18216/1/ MANUALSEGURANCAQUALIDADEaviculturadepostura. pdf

3.Henzler, DJ, Kradel, DC, Sischo, WM. Management and environmental risk factors for Salmonella enteritidis contamination of eggs. Am. J. Vet. Res. 1998 jul; v.59 (7):824829.

4.Stringhini MLF, Andrade MA, Mesquita AJ, Rocha TR, Rezende PM, Leandro NSM. Características bacteriológicas de ovos lavados e não lavados de granjas de produção comercial. Cien. Anim. bras. 2009 dec; 10(4): 1317-1327.

5.Cardoso ALSP, Tessari ENC, Castro AGM, Kanashiro MI, Gama NMSQ. Pesquisa de coliformes totais e coliformes fecais analisados em ovos comerciais no laboratório de patologia avícola de descalvado. Arq. Inst. Biol. 2001 jan; 68(1): 19-22.

6.Aragon-Alegro LC, Souza KLO, Sobrinho PSC, Landgraf M, Destro MT. Avaliação da qualidade microbiológica de ovo integral pasteurizado produzido com e sem a etapa de lavagem no processamento. Ciênc. Tecnol. Aliment. 2005 mar, 25(3): 618-622.

7.Mendes FR, Andrade MA, Café MB, Santos JS, Lacerda
MJR, Stringhini JH, Stringhini ML, Leandro NSM. Physical and chemical quality of sanitized commercial eggs experimentally contaminated with Pseudomonas aeruginosa and refrigerated during storage. R. Bras. Zootec.2012 oct;41(10):2211-2218.

8.De Reu K, Grijspeerdt K, Messens W, Heyndrickx M, Uyttendaele M, Debevere J, Herman L. Eggshell factors influencing eggshell penetration and whole egg contamination by different bacteria, including Salmonella Enteritidis. Int. J. Food Microbiol. 2006 mar; 113(3): 253-260.

9. Andrade MA, Cafe MB, Jayme VS, Rocha PT, Leandro NSM, Stringhini JH. Avaliação da qualidade bacteriológica de ovos de galinha comercializados em Goiânia. Goiás. Brasil. Cien. Anim. bras. 2004 out/dez; 5(4):221-228.

10.SAS Institute. Statistical Analysis System: user guide [CDROM]. Version 8. Cary (NC): SAS Insitute Inc., 2002.

11.Pinto AT, Silva EN. Ensaios de penetração de Salmonella Enteritidis em ovos de galinha com diferentes qualidades de casca, submetidos ou não a lavagem industrial e a duas temperaturas de armazenagem. Arq. Bras. Med. Vet. Zootec. 2009 may; 61(5):1196-1202.

12.Jones DR, Curtis PA, Anderson KE, Jones FT. Microbial contamination in inoculated shell eggs. II. Effects of layer strain and egg storage. Poult. Sci. 2004 jan. 83(1): 95-100.

13.Carvalho FB, Stringhini JH, Jardim Filho RM, Leandro NSM, Cafe MB, Deus HASB. Qualidade interna e de casca para ovos de poedeiras comerciais de diferentes linhagens e idades. Cien. Anim. bras.. 2007 jan/mar; 8(1): 25-29.

14.Franco BDGM, Landgraf M. Microbiologia dos alimentos. São Paulo: Atheneu, 2002. 182 p.

15.Barancelli GV, Martin JGP, Porto E .Salmonella em ovos: relação entre produção e consumo seguro. Segurança Alimentar e Nutricional. 2012 feb, 19(2): 73-82.

16. Figueiredo TD, Viegas RP, Lara LJC, Baião NC, Souza MR, Heneine LGD, Cancado SV. Bioactive amines and internal quality of commercial eggs. Poult. Sci. 2013 may, 92(5):13761384. 